\title{
§ 13 IVV: Information über die Vergütungssysteme
}

Eine schriftliche Unterrichtung der Mitarbeiter nach § 13 Abs. 1 IVV meint in der Sache nicht nur eine Informations-, sondern auch eine Dokumentationspflicht. Dies stellt der Entwurf der Auslegungshilfe zu § 13 IVV auch noch einmal ausdrücklich klar, wenn sie eine Dokumentation des Beurteilungsprozesses im Hinblick auf die individuelle Leistung fordert.

$\mathrm{Zu}$ den aufsichtsrechtlichen Dokumentationspflichten kommen auch noch mitbestimmungsrechtliche Pflichten hinzu, denn bei Bestehen einer Betriebsvereinbarung zur Zielfestlegung und Leistungsbewertung ist der Arbeitgeber verpflichtet, individuelle Zielvereinbarungen und die damit einhergehenden Informationen dem Betriebsrat vorzulegen (LAG Niedersachsen Beschluss vom 1. November 2016 - 3 TaBV 32/15, juris).

Von § 13 IVV bleibt ferner auch ein individueller Auskunftsanspruch nach $\S \S 10$ ff. des am 6. Juli 2017 in Kraft getretenen Entgelttransparenzgesetzes (siehe dazu Franzen 2017, S. 814 ff.) unberührt.

Aufsichtsrechtliche Transparenzgebote und Dokumentationspflichten entfalten keinen Drittschutz zugunsten der Mitarbeiter im Verhältnis zu ihrem Arbeitgeber (vgl. auch Sammet 2013, S. 67 ff.). 